\section{THE WELLBEING OF PEOPLE WITH YOUNGER ONSET DEMENTIA IN AGED-CARE FACILITIES}

\section{Kelly Lambert ${ }^{1}$, Jacqueline McIntosh ${ }^{2}$, Bruno Marques $^{3}$}

${ }^{1}$ Postgraduate student Victoria University of Wellington, ${ }^{2}$ Senior Lecturer Victoria University of Wellington, ${ }^{3}$ Lecturer Victoria University of Wellington, PO Box 600, Wellington, NZ

Jacqueline.mcintosh@vuw.ac.nz,Bruno.marques@vuw.ac.nz

\begin{abstract}
The World Health Organisation suggests that younger onset dementia (YOD) requires specific consideration as it often affects people who are physically fit, socially more active, employed with dependent children and whose behaviour may be more challenging for care givers. Currently, there are no specialised services for people with YOD in New Zealand and people with more advanced YOD requiring care outside their home are placed in aged care facilities. The paper explores the design ideas that provide therapeutic resources or remove barriers to quality of life and wellbeing. Themes of memory, autonomy and therapy were found to have most relevance to well-being. Design can provide sensory stimulation and opportunity for greater physical, social and community engagement and contain, accumulate and project memories in a way which stimulate and inspire reminiscing and imagining. Institutional aged care facilities do not provide these cues for those with YOD. The quality of life of people with YOD and their family care givers can be seriously compromised due to a lack of specialised facilities and services. The default to services designed for the frail and elderly is inappropriate and unsatisfactory.
\end{abstract}

Keywords: younger onset dementia, wellbeing, aged care facilities, dementia

\section{Introduction}

Most people are familiar with dementia, but few realise that it is not just an old persons' disease. Younger onset dementia (YOD) is defined as the onset of dementia before age 65, some afflicted are as young as 30 . People with YOD often have children at home, were recently employed, are physically fit and have active social lives. There are currently no facilities in New Zealand for people with YOD, resulting in their institutionalisation in aged-care facilities withdrawn from the local community and environment. The loss of physical and social stimulation often results in confusion, high anxiety and a faster progression of symptoms.

"For one third of New Zealanders, dementia is one of the things feared most about ageing" (Alzheimer's New Zealand, 2012). When someone who is young gets dementia, loved ones will often try to hide it. This fear combined with the general opinion that dementia is an old person's disease often has negative consequences. These can include; late or misdiagnosis, a lack of understanding amongst family, friends and co-workers, and a faster progression of symptoms. With the inevitable progression of their condition, those with YOD lose their jobs and are often locked away in their own homes for safety. When the family members can no longer cope, the person is institutionalised in an aged-care facility designed for the frail elderly.

People with YOD spend their final years surrounded by frail residents old enough to be their parents (Heather, 2014). Their challenges and needs differ enormously from those suffering from dementia in their elder years. International studies (Haase, 2005; Bakker et al, 2010) have identified a strong need for daycare, respite and long term homes designed to cater specifically for this younger generation. Qualitative research with those with YOD and their carers in the Wellington region supports these findings within the context of New Zealand (Rimkeit, Mclntosh and Lambert, 2014).

Aged-care facilities impose a change in social context and physical activity for those with YOD. In this environment, they are faced with locked doors and docile, unstimulating games rather than the physical or mental activity that they are accustomed to. There is a clear need for age appropriate care which can reduce the loss of memory, autonomy and control those with YOD.

\section{Literature Review}

\section{Memory}

Architectural researchers and practitioners have suggested that architecture can contain, accumulate, and project memory in a way which stimulates and inspires reminiscing and imagination (Oter-Pailos 2008; Pallasmaa, 1985; Treib, 2013). Pallasmaa maintains that architecture becomes more memorable and meaningful when it "sensitises our whole physical and mental receptivity". Similar ideas have been expressed in the medical literature. "People with dementia depend upon a familiar setting that provides cues to enable independent functioning" (Van Hoof, 2010 p9). The shift from home to an institution can therefore mean a loss of all familiar mechanisms associated with 'dwelling' and place.

Ola Nylander, identified seven fields of architectural attributes which enable our perception of these qualitative aspects of home, which make it familiar. These include; materials and detailing, enclosure, movement, spatial figure, daylight, and organisation of spaces (2002). A design which considers these aspects enables the process of appropriation and creation of meaning ensuring an environment which feels like home to its occupants.

In this regard, research supports the use of smaller scale home-like settings for YOD facilities, developing "more interaction between residents, less depression and a lower rate of general decline, than for people living in conventional residential settings" (Lewis, 2002 p27). By recreating an environment akin to the experience of home those with YOD are armed with familiar mechanisms to enable spatial recall.

Within urban theory, Lynch argues that the image of a place is built up of three components; identity, structure and meaning (1960). This concept offers the designer a functional framework with the ability to place an object (identity) within a layout (structure) in order to conjure meaning. Architects who relate their design to knowledge of cognitive psychology may find themselves involved in a universal linguistic system not founded on historic styles or geometric combinations, but on human experience with, and understanding of, architecture (Burnette, 1974). Such a method promotes a design which is based on the first principles governing an individual's understanding of space rather than being solely reliant on past associations.

According to psychiatrist Sivadon, the mentally ill encounter their environment as "a world which derives its meaning from essentially spatial relationships rather than cultural layers" (1970 p410). Consequently there is a need to consider the role of architecture when recollection can no longer occur. By utilising Burnette's ideas the gradual loss of past experiences can be compensated by the individual's basic understanding of spatial relationships. 


\section{Autonomy}

People with YOD are often still physically active and frequently mention the desire for a sense of normalcy (Beattie et al. 2004). However, the progression of their symptoms leads to a gradual erosion of this ability and a loss of autonomy. It has been widely acknowledged that understandable and orienting design, accessibility, privacy and safety are all physical features which lead to a higher level of independence and consequently a reduction in agitation, aggression, and overall psychotic problems (Chafetz and Namazi, 2003; Smith, Mathews and Gresham 2010; Zeisel et al.,2003).

Architectural design can reduce the stigma of dementia care facilities and promote social inclusion. Recent Danish architects have focused on "domestic spaces that remind the users of, and feel like, their own homes, breaking down preconceptions of the nursing home stereotype" and integrating nature and landscape "not as decorative or passive elements, but as key programmatic aspects for healing and health" (Peters, 2014 p49). Robinson and Thompson support these concepts and suggest that residents within a homelike setting have more independently generated behaviours and significantly less stereotypic repetitive behaviours (1999).

Dr Gesine Marquardt, an expert in architectural design for dementia, states that "the design of the physical environment plays a major role in supporting the wayfinding abilities of people with dementia" leading to "autonomy and independence and thereby promoting self-sufficiency and self-esteem"(2011). According to Marquardt, a design which encourages wayfinding can operate on two levels, through floor plan typology and through environmental cues such as signage, furnishings, lighting, colour, etc. (2011).

A medical study conducted in 1997 by Elmstahl, Annerstedt \& Alhund analysing the spatial orientation in living facilities for dementia patients with regard to L-shaped, $\mathrm{H}$-shaped, squareshaped, and double-loaded straight corridor floor plans. The L-shaped design exhibited the least amount of disorientation whereas the corridor design identified more dyspraxia, lack of vitality and disorientation of identity. Another medical study in 1989 by Netten compared cluster facilities with traditional large scale communal facilities. The cluster design achieved a higher level of orientation due to shortened corridors, and simple decision points (1989).

In addition to the overall layout, internal configuration is important to improve wayfinding for those with YOD. Passini et al. identified these as; clear reference points and places, articulated and distinct architectural environments, direct visual access to common areas, simple circulation with wide hallways, and small scale settings (2000). Architectural features to be avoided in order to improve wayfinding include; routes with many exit points, repetitive elements, and elevators (Marquardt 2011).

Environmental cues such as signage, objects, colour, and lighting can also aid in promoting autonomy. Namazi, Rosner, and Rechlin have identified that: signs and pictograms help with locating services such as bathrooms and allowing for personalisation through memorabilia displayed outside rooms helps identification. Vivid colour coding helps enhance short term memory and improve functional ability (1991). Heavily contrasted floors are to be avoided as these are often perceived by people with dementia as a change in depth (Passini et al. 2000). Issues with perception are frequent for those with YOD, therefore, providing sufficient lighting, both natural and artificial can significantly improve wayfinding abilities (Netten, 1989).
These aids enhance controllability over situations or events, which is linked to lower appraisals of stress amongst YOD.

Safety is also important for those with dementia. Wandering residents who try to 'escape' are frequently mentioned, however, constant surveillance is an intrusion on the individual's privacy and independence. Effective safety measures often exploit residents cognitive deficits, through; the use of mirrors on exit doors causing the resident to assume a stranger is approaching (Mayer and Darby 1991), grids of black tape on the floor in front of doors causing avoidance related to confusion with depth (Hewawasam 1996), or hiding the door knob behind blinds or a piece of cloth (Dickinson, McLain-Kark and Marshall-Baker 1995). Such methods prevent the agitation and frustration usually associated with continually locked doors and feelings of imprisonment (Fleming, Crookes and Sum 2008). Fleming et al's literature review, supports this use of unobtrusive safety features and warns against over emphasis on safety as, ultimately, reducing the autonomy of individuals (2008).

\section{Therapy}

Issues with both sensory overstimulation and sensory deprivation are prevalent for those with YOD within care environments. As young and fit people they have considerably more energy and are willing and able to engage in physical activity. As a result, "caring for a younger person can be more demanding and difficult" (Tyson, 2007 p26). It is suggested that design can help by providing "therapeutic resource to promote well-being and functionality among people with dementia" (Day, Carreon and Stump, 2000 p397). Connections to nature, physical exercise, social interaction, and multi-sensory elements can all aid in providing balanced stimulation and therapeutic resource for those affected by YOD.

Connection between the internal environment and the outdoors is dependent on the configuration of programme, orientation of rooms, and location of doors and fenestrations. Providing multiple points for sunlight access can allow residents to orientate themselves according to time of day and season of the year simply through an understanding of sun angle (Gibson et al. 2007). Knowles supports an architecture which draws from the rhythm of nature as a provider of ritual and maintainer of both "comfort and joy in our buildings" (2006 pxv). There is a clear need to consider shelter and protection and acknowledge "the dialectical tension between the attempt at concealing the inside from the outside and yet revealing it, between barring the intrusion of outside while simultaneously taking account of it" (Arnheim, Zucker and Watterson 1966 p12).

Physical activity has been shown to "significantly and substantially improve cognitive ability" due to an improvement in cardiovascular factors and emotional stimulation (Gibson et al. 58). Interviews have revealed walking as the most common form of exercise for those with YOD. A movement channel which allows continual wandering without getting lost is beneficial as a way to harness the tendency for wandering. For those with YOD, embracing and offering opportunities to wander and be active in the garden can contribute towards self-confidence and social interaction, feelings of self-worth, hopefulness, and enjoyment (Gibson et al. 62).

Social interaction is also important to keep the mind actively engaged. Many expressed their frustration with being forced to interact with people much older than themselves (Rimkeit, Mclntosh and Lambert, 2014). Moore and Verhoef's medical study highlights ways to enable social interaction by providing a; home like setting, linking 'wandering paths' between spaces, views to 
activity settings from living areas, choices in social environments for both small or large groups, and layout of furniture conducive to socialising (1999). Each of these components can aid in providing a therapeutic place with high social affordance.

\section{Conclusion}

Advice on the design of environments specifically for those with YOD is lacking in both the architectural and psychiatric literature. This review has grouped research into three main themes: memory, autonomy, and therapy to identify the key issues for those with dementia as well as those items that are specific to YOD. Younger people with dementia differ significantly from those with later onset dementia and as a result they have a distinct set of needs.

A design which provides a memorable and familiar sense of place is important for the well-being of those with YOD. As their ability to recall diminishes a design which provides essential spatial relationships can aid in maintaining an understanding of place in a more instinctual manner. "A prerequisite to maintaining residents' quality of life in a nursing home is their ability to orient themselves within their new environment" (Marquardt, 2011 p75). A quality design that is orientating, private, and safe can reduce the stigma associated with YOD and enhance their sense of autonomy. A stimulating architecture which integrates with; nature, community, physical exercise, and multi-sensory elements can provide a therapeutic environment and help to minimise and/or delay symptoms of YOD.

\section{Bibliography}

Alzheimer's New Zealand. "Dementia Facts and Figures." 2012 Web. 25 November 2014.

Arnheim, Rudolf, Wolfgang M Zucker, and Joseph Watterson. "Inside and Outside in Architecture: A Symposium." Journal of Aesthetics and Art Criticism (1966): 3-15. Print.

Bakker, Christian, et al. "Needs in Early Onset Dementia: A Qualitative Case from the Needy Study." American journal of Alzheimer's disease and other dementias 25.8 (2010): 634-40. Print.

Beattie, Angela, et al. "'How Can They Tell? 'a Qualitative Study of the Views of Younger People About Their Dementia and Dementia Care Services." Health \& social care in the community 12.4 (2004): 359-68. Print.

Burnette, Charles. "The Mental Image and Design." Designing for Human Behaviour. Eds. Lang, J, et al. Stroudsbourg, Pennsylvania: Dowden, Hutchinson and Ross Inc, , 1974. 169-82. Print.

Chafetz, P, and K Namazi. "Structuring Environments for Persons with Cognitive Impairment." The Dementias. Diagnosis, Treatment, and Research. Eds. Weiner, $M$ and A Lipton. Washington DC: American Psychiatric Publishing, 2003. 405-32. Print.

Cutler, Lois J, and Rosalie A Kane. "Environments for Privacy, Safety, and Movement of Persons with Dementia Maximal Privacy+ Moderate Barriers= Minimal Intrusion." Alzheimer's Care Today 3.1 (2002): 50-54. Print.

Day, Kristen, Daisy Carreon, and Cheryl Stump. "The Therapeutic Design of Environments for People with Dementia a Review of the Empirical Research." The Gerontologist 40.4 (2000): 397-416. Print.

Dickinson, Joan Ivers, Joan McLain-Kark, and Anna Marshall-Baker. "The Effects of Visual Barriers on Exiting Behavior in a Dementia Care Unit." The Gerontologist 35.1 (1995): 127-31. Print.
Elmståhl S1, Annerstedt L, Ahlund O. 1997 How should a group living unit for demented elderly be designed to decrease psychiatric symptoms? Alzheimer Dis Assoc Disord. Mar;11(1):4752.

Fleming, Richard, Patrick Crookes, and Shima Sum. A Review of the Empirical Literature on the Design of Physical Environments for People with Dementia: Australian Government, 2008. Print.

Gibson, Grant, et al. "Housing and Connection to Nature for People with Dementia: Findings from the Independent Project." Journal of Housing for the Elderly 21.1-2 (2007): 55-72. Print.

Haase, Trutz. Early-Onset Dementia: A Needs Analysis of Younger People with Dementia in Ireland. Dublin: Alzheimer Society of Ireland, 2005. Print.

Heather, Ben. "42 and Scared of Dementia." 2014. Web. 5 December 2014. http://www.stuff.co.nz/life-style/wellgood/10414490/42-and-scared-of-dementia

Hewawasam, Lucksri C. "The Use of Two-Dimensional Grid Patterns to Limit Hazardous Ambulation in Elderly Patients with Alzheimer's Disease." Nursing Times Research 1.3 (1996): 217-27. Print.

Knowles, Ralph. Ritual House: Drawing on Nature's Rhythms for Architecture and Urban Design. Island Press, 2006. Print.

Lewis, Hazel. Dementia in New Zealand: Improving Quality in Residential Care. Wellington: Ministry of Health, 2002. Print.

Lynch, Kevin. The Image of the City. Cambridge: The M.I.T Press and Harvard University Press, 1960. Print.

Marquardt, Gesine. "Wayfinding for People with Dementia: A Review of the Role of Architectural Design." Health Environments Research \& Design Journal (HERD) 4.2 (2011).

Mayer, Robert, and Stuart J Darby. "Does a Mirror Deter Wandering in Demented Older People?" International Journal of Geriatric Psychiatry 6.8 (1991): 607-09. Print.

Moore, Keith Diaz, and Rianne Verhoef. "Special Care Units as Places for Social Interaction: Evaluating an Scu's Social Affordance." American Journal of Alzheimer's Disease and Other Dementias 14.4 (1999): 217-29. Print

Namazi, Kevan H, Tena Tarler Rosner, and Linda Rechlin. "LongTerm Memory Cuing to Reduce Visuo-Spatial Disorientation in Alzheimer's Disease Patients in a Special Care Unit." American Journal of Alzheimer's Disease and Other Dementias 6.6 (1991): 10-15.

Netten, Ann. "The Effect of Design of Residential Homes in Creating Dependency among Confused Elderly Residents: A Study of Elderly Demented Residents and Their Ability to Find Their Way around Homes for the Elderly." International Journal of Geriatric Psychiatry 4.3 (1989): 143-53. Print.

Nylander, Ola. Architecture of the Home. West Sussex: John Wiley \& Sons, 2002. Print.

Oter-Pailos, J. "Mnemonic Value and Historic Preservation." Spatial Recall: Memory in Architecture and Landscape. 2008. 240-59. Print.

Pallasmaa, Juhani. The Eyes of the Skin: Architecture and the Senses. John Wiley \& Sons, 2013. Print.

---. "The Geometry of Feeling the Phenomenology of Architecture." The Architecture Reader: Essential writings from Vitruvius to the present (1985): 241-45. Print.

Passini, Romedi, et al. "Wayfinding in a Nursing Home for Advanced Dementia of the Alzheimer's Type." Environment and 
Behavior 32.5 (2000): 684-710.

Peters, Terri. "Socially Inclusive Design in Denmark: The Maturing Landscape." Architectural Design 84.2 (2014): 46-53. Print.

Rimkeit, Sally, Jacqueline Mclntosh, and Kelly Lambert. "Experiencing Place: People with Younger Onset Dementia in 'Aged-Care'." Faculty of Psychiatry of Old Age Conference. 2014. Print.

Robinson, Julia.W, and Travis Thompson. "Stigma and Architecture." Enabling Environments: Measuring the Impact of Environment on Disability and Rehabilitation. Eds. Steinfield, Edward and G.Scott Danford. New York: Plenum Publishers, 1999. Print.

Sivadon, Paul. "Space as Experienced: Therapeutic Implications." Environmental Psychology: Man and His Physical Setting. Eds. Proshansky, et al. New York: Holt, Rinehart, \& Winston, 1970. 2137. Print.

Smith, Ronald, R Mark Mathews, and Meredith Gresham. "Preand Postoccupancy Evaluation of New Dementia Care Cottages." American journal of Alzheimer's disease and other dementias 25.3 (2010): 265-75. Print.

Treib, Marc. Spatial Recall: Memory in Architecture and Landscape. Routledge, 2013. Print

Tyson, Marguerite. Exploring the Needs of Younger People with Dementia in Australia. Alzheimer's Australia, 2007. Print.

Van Hoof, J. "Ageing-in-Place: The Integrated Design of Housing Facilities for People with Dementia." doctoral dissertation). Eindhoven University of Technology, Eindhoven, the Netherlands, 2010. Print.

Zeisel, John, et al. "Environmental Correlates to Behavioral Health Outcomes in Alzheimer's Special Care Units." The Gerontologist 43.5 (2003): 697-711. Print 